\title{
18 YEARS AFTER DRUG POLICY CHANGE IN PORTUGAL - WHERE DO WE STAND?
}

\author{
M. Marguilho ${ }^{1}$, N. Rodrigues $^{1}$, A. Nobre ${ }^{1}$.
}

${ }^{1}$ Centro Hospitalar Psiquiátrico de Lisboa

e-mail address: miriamgmarguilho@campus.ul.pt

\section{INTRODUCTION}

- Portugal stands in a peculiar situation regarding drug policy. In the late 1990s, with one of the highest rates of intravenous heroin users and drug-related deaths, the Portuguese government assembled an expert commission to set guidelines for public policy on illicit drug use.

- In contrast to other countries, where reforms tend to focus on criminalization, this strategy was deliberately health-oriented and humanistic, turning Portugal into the first country in the world to decriminalize use and possession of all illicit drugs.

- Almost 20 years on, the reform still attracts considerable international attention.

\section{OBJECTIVES}

This poster aims to contextualize the Portuguese drug policy in its specific social and political background. It also explores indicators found in institutional reports and attempts to integrate them in an epidemiological and cultural framework.

\section{METHODS}

A non-systematic literature review across scientific databases, such as PubMed and EMBASE, and institutional sources, such as SICAD (Service of Integration in Addictive Behaviour) and EMCDDA (European Monitoring Centre for Drug Addiction), was performed.

\section{RESULTS/DISCUSSION}

Lifetime prevalence of illicit drugs has historically been low in Portugal. Despite this, in the late 1980's and 1990s there was a significant population of intravenous heroin users. Rates of infectious diseases such as HIV, AIDS, Tuberculosis and Hepatitis B and C soared. Drugrelated deaths had increased in Portugal to a peak of 369 in 1999 (an increase of $57 \%$ since 1997). After the reform was implemented, in 2001, several periodic reports have been published. According to the most recent one, from 2017, the lifetime prevalence of any drug use in the Portuguese adult population was $11,7 \%$.
This represents a slight increase compared to 2001, when that number was around $7,8 \%$, chiefly due to cannabis use, with the percentages remaining stable or even decreasing for other substances. Notably, lifetime use of heroin decreased from 2,5\% in 2001 to 0,5\% in 2016/17. However, it is difficult to ascertain whether the increases in some variables are significant or concerning, and to what extent they may be attributable to the reform, rather than a reflexion of an international trend.

Prevalence of any drug use in the 15-64 years-old population

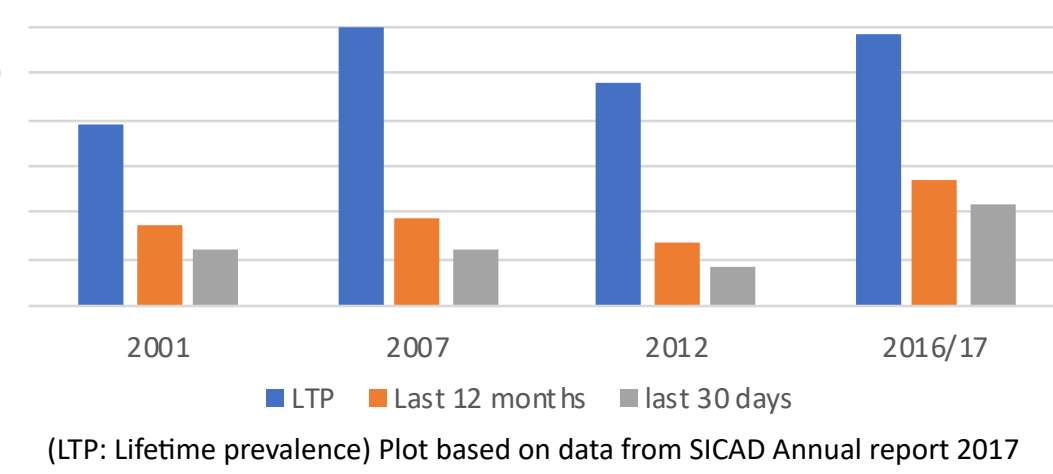

On the other hand, significant declines in drug-related HIV infection (from 1200 cases per year in 2001 to 18 cases in 2016/17), drug-related deaths and crimes strongly linked to drugs have been consistent. These findings are probably related to policies regarding risk reduction in intravenous drug use.

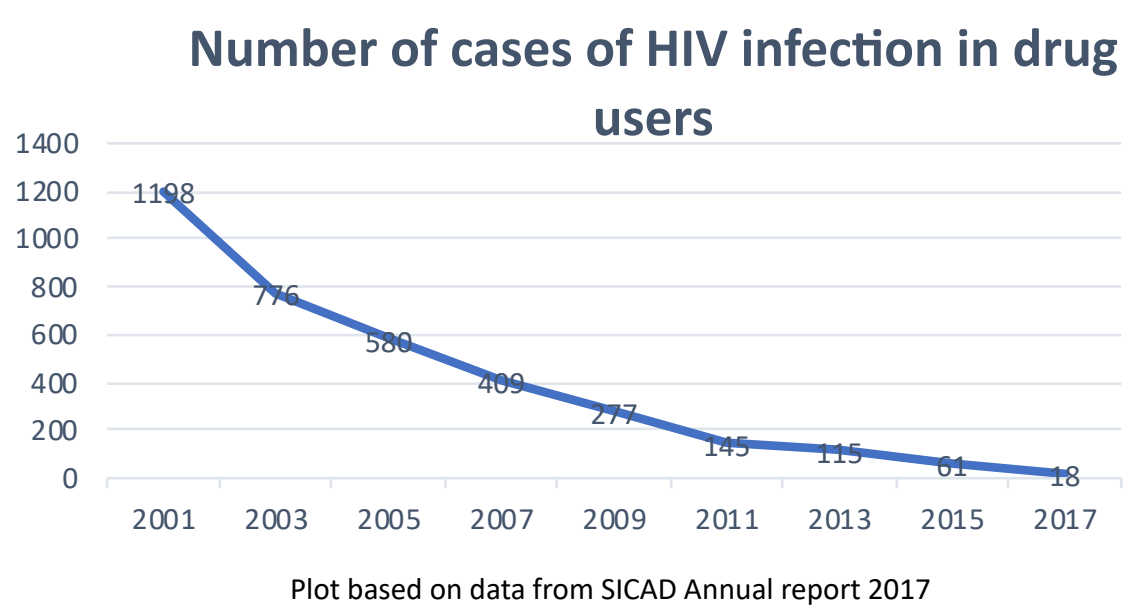

It is also worth noticing that among the 14 European countries where studies among the general population have been conducted since 2015 Portugal stands under the median values regarding recent use of cannabis, cocaine and ecstasy.

\section{CONCLUSIONS}

Eighteen years after decriminalization, although the prevalence of drug use has slightly increased for some drugs, in general, problematic drug use has decreased substantially. These findings show that the Portuguese drug policy has been mostly successful, but the current data also pose some important and new challenges for the upcoming years. 